\title{
Long-Term Effectiveness of Liraglutide in Association with Patients' Baseline Characteristics in Real-Life Setting in Croatia: An Observational, Retrospective, Multicenter Study
}

\author{
Maja Cigrovski Berkovic ·Ines Bilic-Curcic (D) - Davorka Herman Mahecic • Marina Gradiser • \\ Mladen Grgurevic ·Tomislav Bozek
}

Received: September 5, 2017 / Published online: October 26, 2017

(C) The Author(s) 2017. This article is an open access publication

\begin{abstract}
Introduction: Glucagon-like peptide-1 (GLP-1) receptor agonists (RAs) are recommended therapy for type 2 diabetes (T2DM) and liraglutide is the most used worldwide. We assessed the glycemic efficacy and extra-glycemic effects of liraglutide during 36 months' follow-up of individuals with poorly regulated T2DM under routine clinical practice and sought to identify the phenotype of treatment responders.
\end{abstract}

Methods: A total of 207 individuals were included. The primary endpoint was the proportion of participants with HbA1c $<7.0 \%$ and/

Enhanced content To view enhanced content for this article go to http://www.medengine.com/Redeem/ 35CCF06046A471F8.

M. C. Berkovic · D. Herman Mahecic

Department for Endocrinology, Diabetes and

Metabolism University Hospital Centre, Sestre

Milosrdnice, Zagreb, Croatia

I. Bilic-Curcic $(\bowtie)$

Department of Pharmacology, Faculty of Medicine,

J.J. Strossmayer University Osijek, Clinical Hospital

Center Osijek, Osijek, Croatia

e-mail: ibcurcic@mefos.hr

M. Gradiser

Department for Internal Medicine, General Hospital

Čakovec, Čakovec, Croatia

M. Grgurevic · T. Bozek

University Clinic for Diabetes Vuk Vrhovac, Zagreb, Croatia or weight reduction. Secondary endpoints included changes in lipids, blood pressure, fasting c-peptide, and antidiabetic treatment during follow-up of 3 years.

Results: Liraglutide was prescribed to $89.8 \%$ of participants already on at least two antidiabetic medications and $18 \%$ on insulin. Subject's mean age was $53.28 \pm 9.42$ years with duration of diabetes $8.29 \pm 4.89$ years. Baseline $\mathrm{HbA} 1 \mathrm{c}$ was $8.5 \pm 1.3 \%$ and body mass index (BMI) was $39 \pm 4.5 \mathrm{~kg} / \mathrm{m}^{2}$. Reduction of HbA1c was observed in $84.4 \%$ of participants, and $89.2 \%$ experienced average weight reduction of $5 \mathrm{~kg}$. A composite outcome (reduction of HbA1c with any weight loss) was achieved in $76.2 \%$ of patients. After 6 months on liraglutide treatment, $38.1 \%$ of participants achieved target HbA1c level $<7 \%$. This effect was maintained for 36 months in $50.8 \%$ of subjects. Increase in c-peptide was evident after 24 months $(p=0.030)$. Participants experienced a significant reduction in systolic blood pressure (BP) $(p=0.003)$, while there was no effect on diastolic BP, lipid profile, or liver enzymes. The number of participants treated with sulfonylurea decreased from $60.8 \%$ to $17.5 \%$, while the number treated with insulin and sodium-glucose co-transporter-2 (SGLT-2) inhibitor increased $(17.6 \%$ to $24.6 \%$ and $2.5 \%$ to $36.8 \%$, respectively). Independent predictors of durability of HbA1c reduction were initial BMI $(p=0.004)$, HbA1c $(p<0.001)$, systolic BP $(p=0.007)$, and cholesterol $(p=0.020)$. 
Moreover, female gender and shorter duration of diabetes were independent predictors for HbA1c reduction.

Conclusion: Liraglutide shows sustained glycemic and extra-glycemic effects when used for treatment of obese poorly regulated individuals with T2DM.

Keywords: Extra-glycemic effects; GLP-1; Glycemic control; Liraglutide; Real-life clinical practice; Type 2 diabetes; Weight loss

\section{INTRODUCTION}

Good glycemic control is the aim in type 2 diabetes treatment, and if implemented early it is associated with the prevention and/or delay of chronic micro- and macrovascular complications [1]. Recently, the importance of a patient-centered approach has been emphasized, which could include the possibility to address the extra-glycemic targets in diabetic patients, including weight, cardiovascular risk factors, and beta cell preservation [2-4]. In this context, glucagon-like peptide-1 receptor agonist (GLP-1RA) therapy represents the opportunity for individuals with type 2 diabetes mellitus to reach glycemic targets without hypoglycemia, and with additional benefits primarily related to weight loss. Liraglutide is a once daily GLP-1RA with proven efficacy and safety through the LEAD clinical trial program [5-10]. The majority of included patients in the LEAD program were obese, had long duration of disease, and added comorbidity. Results suggested the potential for an HbA1c decrease of $1.5 \%$, with low risk of hypoglycemia, reduction of weight $(-1.7 \mathrm{~kg})$, and were all more pronounced when liraglutide was added during earlier stages of the disease [11]. Moreover, published data from the LEADER randomized control trial suggest cardiovascular benefit with liraglutide added to treatment of individuals with high cardiovascular risk [12]. In the real world, however, liraglutide is mainly suggested as a second- and third-line therapeutic agent by different national and international diabetes associations [13]. Nonetheless, data from clinical practice, following patients from 6 to up to
24 months, suggest its favorable effect in the majority of patients either with weight loss or HbA1c reduction. We analyzed the characteristics and long-term treatment success data for 207 patients in Croatia on liraglutide treatment as an add-on to standard of care. In Croatia, liraglutide was launched in September 2013, and according to national health insurance policy it is reimbursed when added to individuals with type 2 diabetes failing glycemic targets on at least two antidiabetic agents, whose BMI exceeds $35 \mathrm{~kg} / \mathrm{m}^{2}$.

The aim was to investigate whether the efficacy of liraglutide observed in randomized controlled trials (RCTs) translates into therapeutic benefits in the Croatian population during routine clinical practice and follow-up period of 36 months.

\section{METHODS}

This observational, retrospective, multicenter study included adults with type 2 diabetes who had liraglutide added to the treatment after failure of at least two antidiabetic agents. Patients were recruited from six tertiary and secondary hospital centers in Croatia (Zagreb, Osijek, and Cakovec). All procedures followed were in accordance with the ethical standards of the responsible committee on human experimentation (institutional and national) and with the Helsinki Declaration of 1964, as revised in 2013. Ethical approval was obtained at participating centers. Electronic records are kept for all individuals treated with liraglutide, and for the purposes of this research data were extracted by treating physicians. All centers participated in patient enrollment equally, thus limiting the recruitment bias. Included for further analysis were data from individuals with type 2 diabetes and poor glycemic control (HbA1c > 7\%), with available data on weight, BMI, blood pressure, aminotransferases, lipid profile, and fasting c-peptide levels. Excluded were patients treated with liraglutide for less than 6 months. Adherence to liraglutide was evaluated by physicians on the basis of what patients reported and clinical judgment. For all patients, the following data were collected at baseline and control visits: age, duration of 
diabetes, sex, diabetic medications, HbA1c, weight, height, BMI, systolic and diastolic blood pressure, fasting and postprandial blood glucose levels, creatinine, aminotransferases (ALT, AST), lipid profile (total cholesterol, LDL-cholesterol, HDL-cholesterol, triglycerides), and where available fasting c-peptide levels. The fasting blood glucose levels, HbA1c, lipid profile, aminotransferases, and c-peptide levels were measured before follow-up visit in laboratories using standardized methods for quantification, while postprandial blood glucose was measured by patients as a part of self-monitoring of blood glucose (SMBG). Blood pressure and weight were collected at each follow-up visit; no control is available with regard to the scales and blood pressure monitors used for these measurements. Liraglutide titration started with dose of $0.6 \mathrm{mg}$ sc once daily for a week, followed by $1.2 \mathrm{mg}$ sc once daily, followed by a maximal dose of $1.8 \mathrm{mg}$ daily. The time frame for dose escalation from 1.2 to $1.8 \mathrm{mg}$ daily was at the physician's discretion, but not shorter than a week. Participants were followed during outpatient visits after $6,12,18,24$, and 36 months. Changes in HbA1c, fasting blood glucose (FBG), postprandial blood glucose (PPG), weight, BMI, blood pressure, aminotransferases, lipids, and fasting c-peptide levels were assessed and analyzed. Moreover, an evaluation of the maintenance dose of liraglutide and changes in combined antidiabetic treatments was investigated. The primary study endpoint was the proportion of participants with HbA1c $<7.0 \%$ and/or BMI reduction. Secondary endpoints included changes in lipids, blood pressure, fasting c-peptide, and antidiabetic treatment during follow-up of up to 3 years.

\section{Statistical Methods}

Descriptive statistics was used to describe the basic features of the sample in a study (relative frequencies for categorical data, and mean \pm standard deviation for normally distributed continuous variables, or median and interquartile range for variables deviating from normal distribution). Binary or categorical outcome variables were analyzed with Chi square test when testing for differences in observed frequencies. For testing statistical significance of differences between independent groups, ANOVA was used whenever variance was homogenous (tested by Levene's test of equality of variances). For repeated measures (paired samples) paired $t$ test for two measurements and repeated-measures ANOVA (one-way and two-way repeated measures ANOVA) for three or more measurement points were used. Binary logistic regression was used to identify predictors increasing odds for HbA1c reduction (binary dependent variable), and linear regression analysis was used when the dependent variable was measured on a continuous scale. Most baseline characteristics were included in the regression analysis model. Variables were entered and pairwise method was used for treating missings (extraced varible by varible). All statistical comparisons are two-tailed and they were considered significant at the $p<0.05$.

\section{RESULTS}

\section{Participants' Characteristics}

A total of 207 adults with type 2 diabetes were included in the present analysis. There were 95 (45.9\%) men and 112 (54.1\%) women, mean age $53.28 \pm 9.42$ years, who had liraglutide added to the treatment after an average of $8.29 \pm 4.89$ years of diabetes duration. Baseline $\mathrm{HbA1c}$ was $8.5 \pm 1.3 \%$, with average BMI $39 \pm 4.5 \mathrm{~kg} / \mathrm{m}^{2}$. We included patients who were treated with liraglutide for at least 6 and up to 36 months. There were $71.0 \%$ of subjects who were followed for 6 months, $66.7 \%$ for 12 months, $61.8 \%$ for 18 months, $39.1 \%$ for 24 months, and $29.5 \%$ for 36 months. The majority of participants received $1.8 \mathrm{mg}$ doses of liraglutide (64.9\% vs $33.8 \%$ on $1.2 \mathrm{mg}$ dose). Baseline characteristics of participants are summarized in Table 1 . Before initiating liraglutide, $182(88 \%)$ were on metformin, 123 (59\%) on sulfonylurea, 94 (45\%) on dipeptidyl peptidase-4 (DPP-4) inhibitors, and a small number $(5 \%)$ were switching to liraglutide from exenatide, 5 participants (2\%) received sodiumglucose co-transporter-2 inhibitors (SGLT-2i), while $38(18 \%)$ were on insulin before liraglutide initiation. As many as 185 (89.8\%) participants were on a combination therapy of two and three 
Table 1 Parameters of glucoregulation, including blood pressure, lipid profile, and liver enzymes after follow-up period of 36 months

\begin{tabular}{|c|c|c|c|c|c|c|c|c|c|c|c|c|}
\hline & \multicolumn{2}{|c|}{ Baseline } & \multicolumn{2}{|c|}{$\begin{array}{l}\text { After } \\
6 \text { months of } \\
\text { treatment }\end{array}$} & \multicolumn{2}{|c|}{$\begin{array}{l}\text { After } \\
12 \text { months of } \\
\text { treatment }\end{array}$} & \multicolumn{2}{|c|}{$\begin{array}{l}\text { After } \\
18 \text { months of } \\
\text { treatment }\end{array}$} & \multicolumn{2}{|c|}{$\begin{array}{l}\text { After } \\
24 \text { months of } \\
\text { treatment }\end{array}$} & \multicolumn{2}{|c|}{$\begin{array}{l}\text { After } \\
36 \text { months of } \\
\text { treatment }\end{array}$} \\
\hline & Mean & SD & Mean & SD & Mean & SD & Mean & SD & Mean & SD & Mean & SD \\
\hline BMI, $\mathrm{kg} / \mathrm{m}^{2}$ & 39.02 & 4.46 & $36.71^{*}$ & 3.86 & $36.38^{*}$ & 3.70 & $36.49^{*}$ & 3.57 & $36.38^{*}$ & 3.48 & $36.49^{*}$ & 3.30 \\
\hline HbAlc \% & 8.49 & 1.29 & $7.32^{*}$ & 0.97 & $7.27^{*}$ & 1.06 & $7.26^{*}$ & 1.08 & $7.39^{*}$ & 1.32 & $7.06^{*}$ & 0.85 \\
\hline FBG, $\mathrm{mmol} / \mathrm{l}$ & 10.17 & 2.86 & $7.69^{*}$ & 2.28 & $7.57^{*}$ & 1.86 & $7.38^{*}$ & 1.75 & $7.85^{*}$ & 2.61 & $7.19^{*}$ & 1.66 \\
\hline PPG, mmol/l & 11.85 & 3.07 & $9.35^{*}$ & 2.17 & $9.07^{*}$ & 2.59 & $8.59^{*}$ & 2.15 & $8.67^{*}$ & 1.94 & $8.30^{*}$ & 1.26 \\
\hline $\begin{array}{c}\text { Cholesterol, } \\
\mathrm{mmol} / \mathrm{l}\end{array}$ & 5.09 & 1.09 & 4.79 & 0.97 & 4.76 & 1.01 & 4.60 & 0.91 & 4.78 & 0.96 & 4.61 & 0.63 \\
\hline $\mathrm{HDL}, \mathrm{mmol} / \mathrm{l}$ & 1.21 & 0.43 & 1.19 & 0.31 & 1.14 & 0.29 & 1.19 & 0.24 & 1.20 & 0.26 & 1.13 & 0.28 \\
\hline LDL, mmol/l & 3.04 & 0.98 & 2.78 & 0.88 & 2.80 & 0.88 & 2.81 & 0.79 & 3.08 & 2.66 & 2.78 & 0.77 \\
\hline $\begin{array}{l}\text { Triglyceride, } \\
\mathrm{mmol} / \mathrm{l}\end{array}$ & 2.60 & 2.20 & 1.97 & 0.98 & 2.02 & 0.93 & 1.91 & 0.70 & 1.98 & 1.16 & 1.97 & 0.73 \\
\hline AST, mmol/l & 29.55 & 13.07 & 25.58 & 10.97 & 25.36 & 10.65 & 27.57 & 9.73 & 23.93 & 11.17 & 23.14 & 7.23 \\
\hline ALT, mmol/l & 36.97 & 16.15 & 32.19 & 17.36 & 30.20 & 15.56 & 31.07 & 13.68 & 30.86 & 17.57 & 30.95 & 9.48 \\
\hline C-peptide & 1.19 & 0.53 & 1.39 & 0.55 & 1.47 & 0.48 & 1.59 & 0.41 & $1.56^{*}$ & 0.47 & $1.69^{*}$ & 0.32 \\
\hline $\begin{array}{c}\text { Systolic BP, } \\
\mathrm{mmHg}\end{array}$ & 142.97 & 14.05 & $134.41^{*}$ & 10.26 & $135.13^{*}$ & 9.72 & $132.98^{*}$ & 10.88 & 138.01 & 10.63 & $133.51^{*}$ & 8.96 \\
\hline $\begin{array}{c}\text { Diastolic BP, } \\
\mathrm{mmHg}\end{array}$ & 86.68 & 12.86 & 82.17 & 10.79 & 82.93 & 8.34 & 82.47 & 8.48 & 85.41 & 7.49 & 84.36 & 8.78 \\
\hline
\end{tabular}

antidiabetic agents, and a small proportion (3.4\%) received four antidiabetic agents prior to liraglutide introduction.

\section{Glycemic Efficacy, Weight Reduction, and Effect on Extra-Glycemic Parameters}

Parameters of glucoregulation and extraglycemic parameters including blood pressure, lipid profile, and liver enzymes after a follow-up period of 36 months are presented in Table 1 . Repeatedmeasures ANOVA shows a statistically significant decrease in HbA1c, FBG, and PPG in all time points during the follow-up period $(p<0.001)$. The post hoc test shows a significant decrease after 3 months compared to the baseline $(p<0.001)$ that is maintained at all other time points $(p<0.01$ for all) (Fig. 1). Average reduction of HbA1c after 6 months was $1.27 \%$, with further gradual decrease over time, and after 36 months of treatment it reached a reduction of $1.34 \%$ (Fig. 2). A statistically significant decrease in BMI was observed during a period of 36 months $(p<0.001)$ with significant decrease after 3 months compared to the baseline $(p<0.001)$ that is maintained at all other monitoring points (all $p<0.05$ ). Body weight reduction showed the same trend; after 6 months of treatment average weight loss is $5 \mathrm{~kg}$, reaching $7 \mathrm{~kg}$ after 36 months of treatment (Fig. 2).

A significant increase in fasting c-peptide was also present; however, it was visible 24 months after the initiation of liraglutide $(p=0.030)$. 


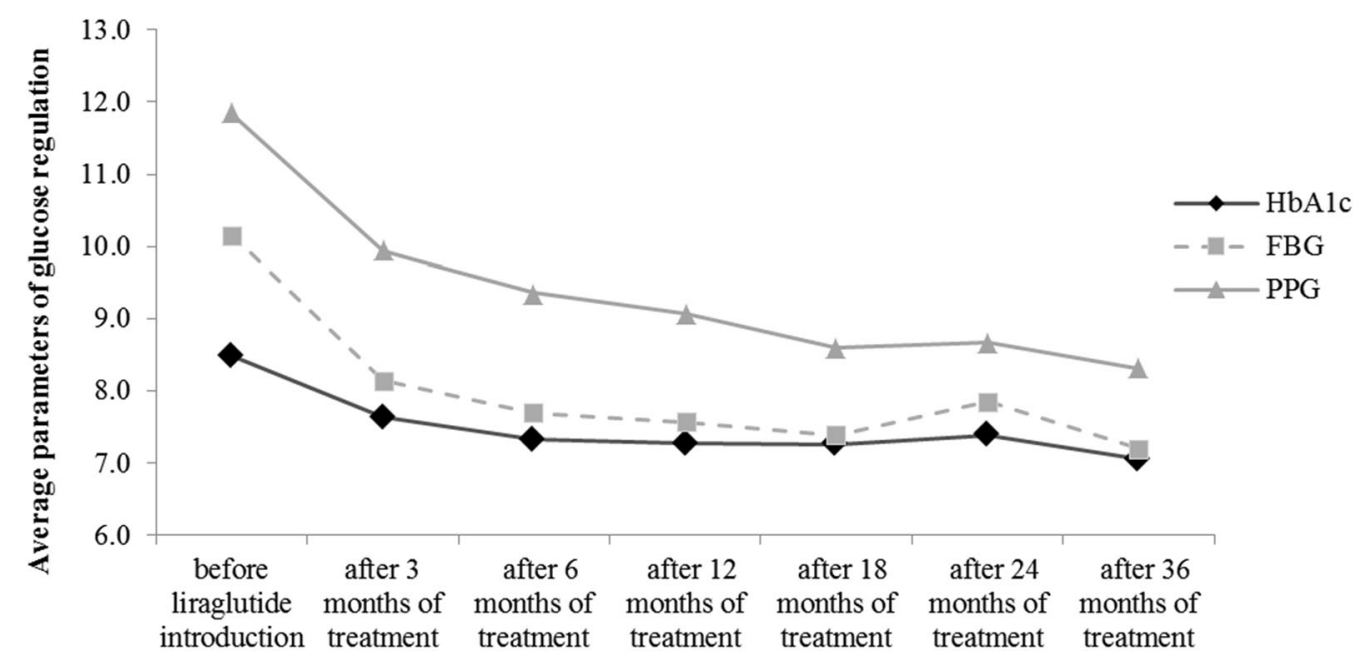

Fig. 1 Parameters of glucoregulation over a period of 36 months
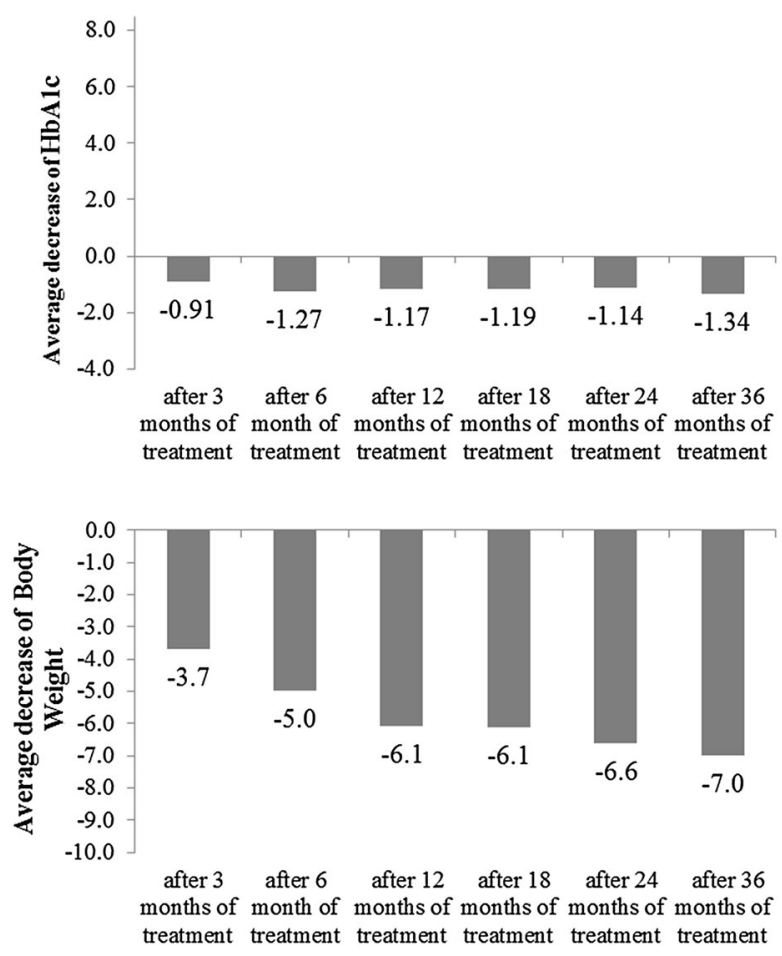

Fig. 2 Average decrease of HbAlc and body weight over a period of 36 months

There were no significant differences in total cholesterol, LDL, HDL, and triglyceride levels as well as liver enzymes. When analyzing blood pressure values, there was a significant reduction in systolic BP $(p=0.003)$. Reduction was already present after 3 months $(p=0.032)$ and, although this reduction was not maintained at all measurement points, systolic BP was significantly lower after 36 months compared to baseline $(p=0.006)$. Changes in diastolic BP were not statistically significant. A series of two-way ANOVAs was used to check the effect of age and duration of diabetes on the regulation of the observed parameters. There was no significant interaction of duration of diabetes and age on observed glycemic and extraglycemic parameters (data not shown).

\section{Relationship Between Liraglutide and Other Antidiabetic Drugs}

In order to analyze changes in concomitant glucose-lowering therapy, patients were divided into groups according to background therapy in the following way: the metformin group was treated with metformin as monotherapy at baseline, later in combination with liraglutide; in the insulin group, patients received insulin in combination with any other glucose-lowering agent; those treated with sulfonylurea (SU) in combination with other oral antidiabetics (OADs) or liraglutide were assigned to the SU group; subjects treated with DPP-4i or SGLT-2i in combination with metformin were assigned to the DPP-4i or SGLT-2i group, respectively; those subjects allotted as other received acarbose or thiazolidinediones in combination with metformin. Over a period of 
36 months, the most noticeable difference was the reduction in the number of patients treated with sulfonylurea (from $60.8 \%$ to $17.5 \%$ ). It was also evident that the number of patients treated with insulin increased slightly (from $17.6 \%$ to $24.6 \%$ ), with significant increase in the use of SGLT-2i (from $2.5 \%$ to $36.8 \%$ ). However, the number of patients treated with metformin alone in combination with liraglutide initially increased in the first 6 months (from $3.4 \%$ to $22.8 \%$ ) followed by a considerable decrease until the end of the follow-up period (from $22.8 \%$ to $14 \%$ ). As was expected after the introduction of liraglutide, no patients were treated with DPP-4i.

\section{Potential Predictors of Successful Response to Liraglutide Therapy}

A composite outcome (reduction of $\mathrm{HbA1c}$ with any weight loss) was achieved by $76.2 \%$ of total participants included in the study, reduction of HbA1c was observed in $84.4 \%$ of participants, while $89.2 \%$ of participants experienced weight reduction (Table 2). In order to define predictors of response to liraglutide, binary logistic regression was performed including all baseline characteristics and only baseline HbA1c and prior insulin therapy were predictive of successful response. However, when we analyzed for statistically significant predictors of HbA1c reduction using linear regression analysis, baseline HbA1c was once again the only

Table 2 Percentage of patients achiving reduction in $\mathrm{HbAlc}$ and BMI after period of 6 months

\begin{tabular}{lcc}
\hline Responders & Number & Percentage \\
\hline $\begin{array}{l}\text { No decrease in either BMI or } \\
\text { HbAlc }\end{array}$ & 3 & 2.5 \\
$\begin{array}{l}\text { Decrease in both BMI and } \\
\quad \text { HbAlc }\end{array}$ & 93 & 76.2 \\
Decrease in BMI & 109 & 89.2 \\
Decrease in HbAlc & 103 & 84.4 \\
HbAlc $>7$ & 79 & 61.9 \\
HbAlc $\leq 7.0 \%$ & 68 & 38.1 \\
\hline
\end{tabular}

predictor after 6 months of GLP-1RA therapy, but after 36 months initial BMI $(p=0.004)$, HbA1c $(p<0.001)$, systolic BP $(p=0.007)$, and initial cholesterol $(p=0.020)$ were all independent predictors of HbA1c reduction (Table 3).

After 6 months on liraglutide treatment $38.1 \%$ of our participants achieved target HbA1c level $<7 \%$ (Table 2). This effect was maintained for 36 months, since $50.8 \%$ of patients at the end of the follow-up period were at the target level (Fig. 3). In this case binary logistic regression analysis showed that male patients have $65 \%$ less chance of achieving HbA1c target level after 6 months (OR 0.35, CI $0.14-0.88, p=0.024)$. Also, a borderline statistically significant variable was duration of diabetes (OR 2.68, CI 0.97-7.40, $p=0.057$ ), indicating that patients with shorter duration of diabetes (3-9 years) had more than two and half times greater chance of reaching HbA1c target after 6 months compared to those suffering from diabetes for more than 10 years (Table 4).

\section{DISCUSSION}

In this multicenter, observational, retrospective analysis following participants on liraglutide from 6 to 36 months, we analyzed baseline phenotype characteristics of type 2 diabetic individuals that could predict longstanding glycemic control and weight-loss maintenance together with additional extraglycemic effects. Data from RCTs on liraglutide have shown favorable results in terms of glycemic control, weight, and recently available results of CVOT suggest cardioprotective effects of liraglutide in a high-risk diabetic patient population $[11,12]$. Oftentimes, individuals with type 2 diabetes in the real-world setting do not share exact characteristics of RCT populations, so data from clinical practice are needed to more closely depict responders to specific therapy [13].

Until now, real-life studies with follow-up mainly up to 24 months have shown the efficacy and safety of liraglutide as a valuable therapeutic option for T2DM treatment [14]. As in our study, most of the published observational studies demonstrated significant 
Table 3 Predictors of $\mathrm{HbAlc}$ reduction after 36 months of liraglutide treatment

\begin{tabular}{|c|c|c|c|}
\hline \multirow[t]{2}{*}{$\begin{array}{l}\text { Linear regression } \\
\text { analysis Model }\end{array}$} & \multicolumn{2}{|c|}{$\begin{array}{l}\text { Standardized } \\
\text { coefficients }\end{array}$} & \multirow[t]{2}{*}{ Significance } \\
\hline & $\overline{\text { Beta }}$ & $t$ & \\
\hline \multicolumn{4}{|l|}{1 (Variable) } \\
\hline (Constant) & & 1.760 & 0.089 \\
\hline Duration of DM & 0.064 & 0.594 & 0.557 \\
\hline $\begin{array}{l}\text { BMI before } \\
\text { liraglutide } \\
\text { introduction }\end{array}$ & -0.314 & -3.188 & $0.004^{*}$ \\
\hline $\begin{array}{l}\text { ALT before } \\
\text { liraglutide treatment }\end{array}$ & -0.034 & -0.238 & 0.813 \\
\hline $\begin{array}{l}\text { AST before } \\
\text { liraglutide treatment }\end{array}$ & -0.243 & -1.737 & 0.093 \\
\hline $\begin{array}{l}\text { HbAlc before } \\
\text { liraglutide } \\
\text { introduction }\end{array}$ & -0.790 & -5.762 & $0.000^{*}$ \\
\hline $\begin{array}{l}\text { FBG before } \\
\text { liraglutide treatment }\end{array}$ & -0.135 & -0.935 & 0.358 \\
\hline $\begin{array}{l}\text { PPG before } \\
\text { liraglutide treatment }\end{array}$ & 0.104 & 0.792 & 0.435 \\
\hline $\begin{array}{l}\text { C-peptide level } \\
\text { before liraglutide } \\
\text { treatment }\end{array}$ & 0.182 & 1.704 & 0.100 \\
\hline $\begin{array}{l}\text { Systolic blood } \\
\text { pressure before } \\
\text { liraglutide treatment }\end{array}$ & 0.305 & 2.893 & $0.007^{*}$ \\
\hline $\begin{array}{l}\text { Diastolic blood } \\
\text { pressure before } \\
\text { liraglutide treatment }\end{array}$ & -0.087 & -0.879 & 0.387 \\
\hline $\begin{array}{l}\text { Cholesterol level } \\
\text { before liraglutide } \\
\text { treatment }\end{array}$ & 0.610 & 2.463 & $0.020^{*}$ \\
\hline $\begin{array}{l}\text { HDL before } \\
\text { liraglutide treatment }\end{array}$ & -0.039 & -0.314 & 0.756 \\
\hline $\begin{array}{l}\text { LDL before } \\
\text { liraglutide treatment }\end{array}$ & -0.431 & -1.919 & 0.065 \\
\hline
\end{tabular}

Table 3 continued

\begin{tabular}{lccc}
\hline $\begin{array}{l}\text { Linear regression } \\
\text { analysis Model }\end{array}$ & \multicolumn{2}{l}{$\begin{array}{l}\text { Standardized } \\
\text { coefficients }\end{array}$} & \multirow{2}{*}{ Significance } \\
\cline { 2 - 3 } & Beta & \multicolumn{1}{c}{$\boldsymbol{t}$} \\
\hline $\begin{array}{l}\text { Triglyceride level } \\
\text { before liraglutide } \\
\text { treatment }\end{array}$ & 0.043 & 0.379 & 0.707 \\
$\begin{array}{l}\text { TSH before } \\
\text { liraglutide treatment }\end{array}$ & 0.017 & 0.172 & 0.865 \\
Age of the patient & 0.031 & 0.310 & 0.759 \\
\hline
\end{tabular}

Linear regression analysis model; ${ }^{*} p<0.05$

$F B G$ fasting blood glucose, $P P G$ postprandial blood glucose, TSH thyroid stimulating hormone

reduction of HbA1c of on average 0.9-2.26\%, which is consistent with LEADER RCT results where $\mathrm{HbA} 1 \mathrm{c}$ reduction ranged from $0.8 \%$ to $1.83 \%$ [15]. Also, in observational studies, one third of the patients achieved target HbA1c $\leq 7 \%$, while as many as $46 \%$ of our patients managed to achieved this goal, as confirmed by LEADER RCT, where $35-45 \%$ of patients reached the HbA1c target [16].

The composite endpoint, which was defined as reduction of HbA1c with any weight loss, was achieved in $76.2 \%$ of our patients which is a rather high percentage compared to the published data so far (16.9-47\%) [16-18], but the reason could be a difference in the definition of composite outcomes since previous studies used the NICE criteria (percentage of patients with HbA1c reduction $\geq 1 \%$ and weight reduction $\geq 3 \%$ ) [19].

Previous studies have shown that liraglutide has a beneficial effect on body weight independent of initial BMI ( -1.3 to $-8.65 \mathrm{~kg})$, but the effect is more pronounced if the initial body mass is greater $[16,20,21]$. In Croatia it is regulated by national health care providers that only individuals with BMI over $35 \mathrm{~kg} / \mathrm{m}^{2}$ receive liraglutide treatment without co-payment, which explains why as many as $89.2 \%$ of our patients had a significant loss of body weight, on average 5-7 kg [22]. 


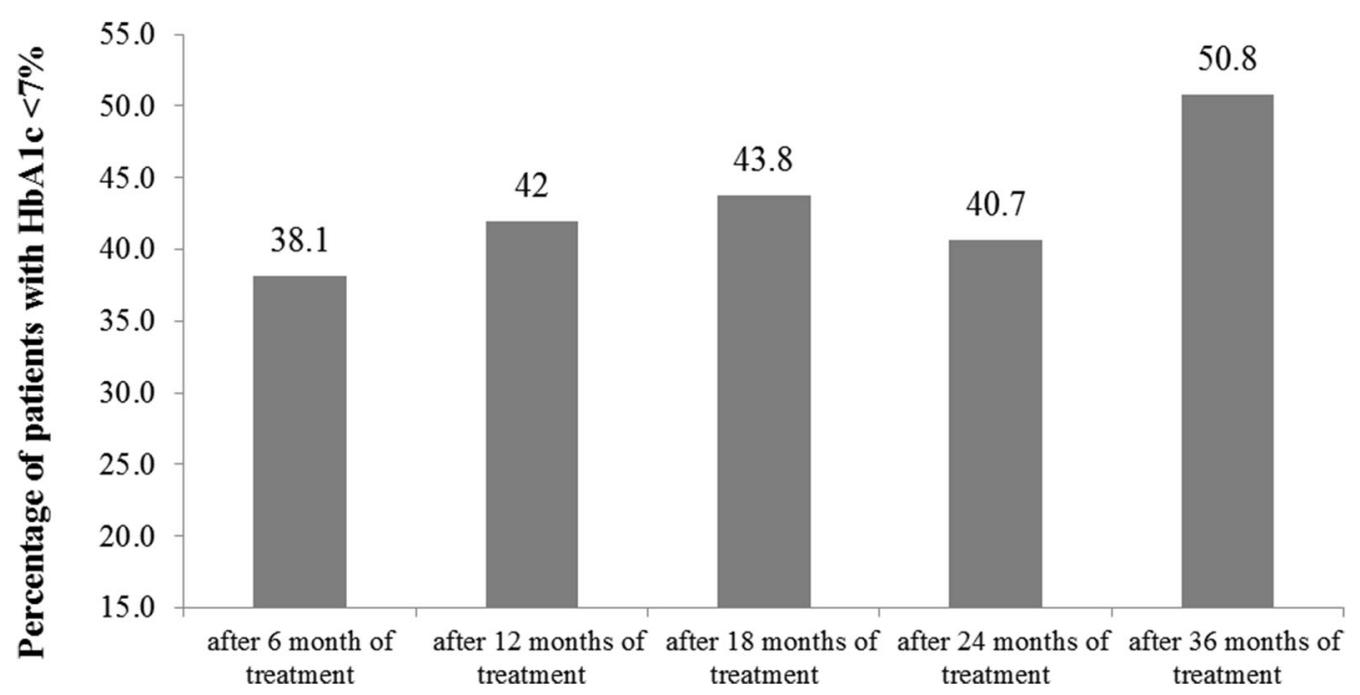

Fig. 3 Percentage of patients achieving HbAlc $<7 \%$ over a period of 36 months

Effectiveness of liraglutide and long-term control over 3 years, which was maintained regardless of previous therapy (including insulin and SU), has been recently demonstrated and is also supported by our findings $[15,20,23]$. In addition, a beneficial effect regarding systolic blood pressure was also noted, but there was no effect on lipid profile observed in other studies $[15,20,23]$. This difference can be explained by the specific phenotype of our participants who all had a BMI above $35 \mathrm{~kg} / \mathrm{m}^{2}$ and statin co-treatment. Hence, liraglutide's effect on lipid profile could not be as pronounced as in other studies including individuals with type 2 diabetes and BMI ranging from 25 to $40 \mathrm{~kg} / \mathrm{m}^{2}$.

C-peptide levels increased with liraglutide treatment supporting the in vivo and in vitro evidence of its effect on improvement and restoration of beta cell function [24, 25].

Meta-analysis of the LEAD program showed improvement of liver enzymes in individuals with type 2 diabetes, mainly explained by weight loss and better glycemic control [26]. In the LEAN study, liraglutide therapy led to histological improvement of non-alcoholic steatohepatitis in T2DM individuals [27]. However, liraglutide therapy had no effect on liver enzymes in our study population, but this was an observational study not designed to primarily observe the effect of GLP-1RA therapy on liver injury, and other confounding factors cannot be neglected such as concomitant OAD and statin therapy.

The most pronounced effect of liraglutide regarding prior antidiabetic therapy is reduction in the use of SU and increase in metformin/liraglutide combination alone. However, the majority of patients treated for 36 months needed therapy intensification either with basal insulin or SGLT-2i for successful maintenance of glycemic control and body weight. Quite surprisingly, in those patients treated for 36 months regardless of therapy intensification, the decrease in HbA1c and body weight was more pronounced than in patients treated for 6 months.

Although glycemic control and extraglycemic effects of GLP-1RA are impressive, one of the major problems is how to differentiate responders from non-responders, and how to predict which group of individuals will successfully respond to liraglutide therapy [28].

Present studies have reported that a short history of diabetes, baseline HbA1c level, insulin therapy, and high fasting serum c-peptide at the treatment initiation may predict response to GLP-1RA in terms of reducing blood glucose levels [20, 29-32]. The aforementioned corresponds to our findings where baseline HbA1c is the strongest predictor of successful response after a period of 6 months. It is interesting to note 
Table 4 Clinical parameters predictive of achieving target value for $\mathrm{HbAlc}(\leq 7 \%)$

\begin{tabular}{|c|c|c|c|}
\hline & Significance & OR & $\begin{array}{l}95 \% \mathrm{CI} \text { for } \\
\operatorname{EXP}(B)\end{array}$ \\
\hline Gender (male) & $0.024^{*}$ & 0.355 & $0.144 \pm 0.875$ \\
\hline $\begin{array}{l}\text { Duration of } \\
\text { diabetes }\end{array}$ & 0.091 & & \\
\hline Up to 2 years & 0.076 & 4.976 & $0.847 \pm 29.240$ \\
\hline $3-9$ years & $0.057^{*}$ & 2.683 & $0.972 \pm 7.404$ \\
\hline Age $(<65)$ & 0.923 & 0.956 & $0.382 \pm 2.390$ \\
\hline $\begin{array}{l}\text { FBG before } \\
\text { liraglutide } \\
\text { treatment (up } \\
\text { to } 7 \mathrm{mmol} \text { ) }\end{array}$ & 0.084 & 4.034 & $0.830 \pm 19.616$ \\
\hline $\begin{array}{l}\text { PPG before } \\
\text { liraglutide } \\
\text { treatment (up to } \\
11.1 \mathrm{mmol} \text { ) }\end{array}$ & 0.111 & 2.080 & $0.846 \pm 5.114$ \\
\hline $\begin{array}{l}\text { Systolic BP before } \\
\text { liraglutide } \\
(\text { normal < 140) }\end{array}$ & 0.240 & 1.814 & $0.672 \pm 4.900$ \\
\hline $\begin{array}{l}\text { Diastolic BP } \\
\text { before liraglutide } \\
(\text { normal }<90)\end{array}$ & 0.571 & 0.764 & $0.301 \pm 1.936$ \\
\hline Insulin & 0.718 & 0.783 & $0.209 \pm 2.942$ \\
\hline SU & 0.560 & 0.728 & $0.251 \pm 2.115$ \\
\hline Incretin & 0.165 & 0.499 & $0.187 \pm 1.331$ \\
\hline Constant & 0.663 & 0.670 & \\
\hline
\end{tabular}

Linear logistic regression analysis model; ${ }^{*} p<0.05$

$F B G$ fasting blood glucose, $P P G$ postprandial blood glucose, $O R$ odds ratio

that prior insulin therapy was associated with liraglutide effectiveness in reducing HbA1c which is actually quite the opposite of recent findings. Again, our patient population was quite specific because of Croatian reimbursement policies where GLP-1RA cannot be used as a second-line treatment, but only a third-line treatment option [22]. Insulin therapy in most cases represents basal insulin in combination with other OADs and this effect is probably mediated by the ability of basal insulin to "rest" the insulin-producing beta cells and thereby enable some recovery of the endogenous prandial insulin response [33]. Furthermore, initial BMI, baseline HbA1c, systolic BP, and initial cholesterol were independent predictors of maintaining significant $\mathrm{HbA} 1 \mathrm{c}$ reduction after 36 months of therapy. Those baseline characteristics which are all components of metabolic syndrome have not been mentioned as potential predictors in the literature so far and this could only support the hypothesis that patients with greater body weight and associated metabolic syndrome benefit most from liraglutide therapy. Moreover, those with shorter duration of diabetes had two and half times greater chance of reaching target HbA1c after 6 months which is in agreement with previous reports $[20,23]$. The probability of reaching target $\mathrm{HbA} 1 \mathrm{c} \leq 7 \%$ was significantly higher in female participants. Interestingly, an impact of female gender on liraglutide glycemic effectiveness was also noted by Lecube et al. and during the INITIATOR study even after adjustment for age, BMI, and duration of diabetes $[34,35]$. Such gender-related differences if similar to animal models could possibly be related to differences in regulation of insulin receptors in satiety centers [36]. Finally, real-world evidence for long-term effectiveness of other GLP-1RAs shows that the mentioned therapy is safe and well tolerated, but when comparison analyses are performed liraglutide is associated with greater reductions in HbA1c and systolic blood pressure than other once daily GLP-1RAs $[37,38]$.

The main limitation of this study is its non-interventional observational design and availability of only routine data from everyday clinical practice. Since data were collected from registries it is possible that some clinical events as well as clinical data were omitted which could influence the interpretation of the performed analysis.

However, this study has significant strengths such as sample size, duration of follow-up, availability of large amounts of clinical information, and very few exclusion criteria (mainly those regarding health policy limitations), making this study analysis applicable to a wide range of diabetes subjects. 


\section{CONCLUSION}

The glycemic and extra-glycemic effects of liraglutide are maintained for up to 3 years regardless of therapy intensification. A high percentage of patients, almost half, managed to achieve HbA1c below 7\%, while the majority managed to lose $5-7 \mathrm{~kg}$ on average. Baseline HbA1c is the strongest predictor of successful response after a period of 6 months followed by prior insulin therapy, shorter duration of diabetes (less than 10 years), and female gender. Initial BMI, baseline $\mathrm{HbA1c}$, systolic BP, and initial cholesterol are independent predictors of maintaining significant $\mathrm{HbA1c}$ reduction after 36 months of therapy. Prior SU therapy does not adversely affect liraglutide efficacy. These data refer to a specific population of patients with BMI over $35 \mathrm{~kg} / \mathrm{m}^{2}$ who received liraglutide after failure of two and more agents and therefore differ somewhat from studies published so far which could be helpful in rational clinical decision-making and cost-effective prescribing of liraglutide.

\section{ACKNOWLEDGEMENTS}

The authors acknowledge the support from Radenka Munjas Samarin, PhD in statistical analyses funded by Novo Nordisk. Funding for the study and publication charges was provided by the authors. All authors had full access to all of the data in this study and take complete responsibility for the integrity of the data and accuracy of the data analysis. All named authors meet the International Committee of Medical Journal Editors (ICMJE) criteria for authorship for this manuscript, take responsibility for the integrity of the work as a whole, and have given final approval for the version to be published.

Disclosures. Maja Cigrovski Berkovic, Ines Bilic-Curcic, Davorka Herman Mahecic, Marina Gradiser, Mladen Grgurevic, and Tomislav Bozek have nothing to disclose.

Compliance with Ethics Guidelines. All procedures followed were in accordance with the ethical standards of the responsible committee on human experimentation (institutional and national) and with the Helsinki Declaration of 1964, as revised in 2013. Informed consent was obtained from all patients for being included in the study. Additional informed consent was obtained from all patients for which identifying information is included in this article.

Open Access. This article is distributed under the terms of the Creative Commons Attribution-NonCommercial 4.0 International License (http://creativecommons.org/licenses/ by-nc/4.0/), which permits any noncommercial use, distribution, and reproduction in any medium, provided you give appropriate credit to the original author(s) and the source, provide a link to the Creative Commons license, and indicate if changes were made.

\section{REFERENCES}

1. American Diabetes Association. Standards of medical care in diabetes 2012. Diabetes Care. 2012;35:S11-S63.

2. Stratton IM, Adler AI, Neil HA, et al. BMJ. 2000;321(7258):405-12.

3. Inzucchi SC, Bergenstal RM, Buse JB, et al. Diabetes Care. 2012;35(6):1364-79.

4. Cornell S. Differentiating among incretin therapies: a multiple-target approach to type 2 diabetes. J Clin Pharm Ther. 2012;37(5):510-24.

5. Marre $\mathrm{M}$, Shaw J, Brandle $\mathrm{M}$, et al. Liraglutide, a once-daily human GLP-1 analogue, added to a sulphonylurea over 26 weeks produces greater improvements in glycaemic and weight control compared with adding rosiglitazone or placebo in subjects with Type 2 diabetes (LEAD-1 SU). Diabet Med. 2009;26(3):268-78.

6. Nauck M, Frid A, Hermansen K, et al. Efficacy and safety comparison of liraglutide, glimepiride, and placebo, all in combination with metformin, in type 2 diabetes: the LEAD (liraglutide effect and action in diabetes)-2 study. Diabetes Care. 2009;32(1):84-90.

7. Garber A, Henry R, Ratner R, et al. Liraglutide versus glimepiride monotherapy for type 2 diabetes 
(LEAD-3 Mono): a randomised, 52-week, phase III, double-blind, parallel-treatment trial. Lancet. 2009;373(9662):473-81.

8. Zinman B, Gerich J, Buse JB, et al. Efficacy and safety of the human glucagon-like peptide- 1 analog liraglutide in combination with metformin and thiazolidinedione in patients with type 2 diabetes (LEAD-4Met+TZD).

Diabetes

Care. 2009;32(7):1224-30.

9. Russell-Jones D, Vaag A, Schmitz O, et al. Liraglutide vs insulin glargine and placebo in combination with metformin and sulfonylurea therapy in type 2 diabetes mellitus (LEAD-5 met+SU): a randomised controlled trial. Diabetologia. 2009;52(10):2046-55.

10. Buse JB, Rosenstock J, Sesti G, et al. Liraglutide once a day versus exenatide twice a day for type 2 diabetes: a 26-week randomised, parallel-group, multinational, open-label trial (LEAD-6). Lancet. 2009;374(9683):39-47.

11. Nauck M, Pratley R, Brett J, Falahati A, Holst J. Adding liraglutide to existing therapy produces greater improvement in glycemic control: evidence from a meta-analysis. Diabetes. 2009;58(Suppl. 1):A122.

12. Kaira S. Follow the LEADER-liraglutide effect and action in diabetes: evaluation of cardiovascular outcome results trial. Diabetes Ther. 2016;7(4):601-9.

13. Inzucchi SE, Bergenstal RM, Buse JB, et al. Management of hyperglycemia in type 2 diabetes, 2015: a patient-centered approach: update to a position statement of the American Diabetes Association and the European Association for the Study of Diabetes. Diabetes Care. 2015;38(1): 140-9.

14. Hannah EL. Randomized clinical trials and observational studies: guidelines for assessing respective strengths and limitations. JACC Cardiovasc Interv. 2008;1:211-7.

15. Lapolla A, Frison V, Bettio M, et al. Correlation between baseline characteristics and clinical outcomes in a large population of diabetes patients treated with liraglutide in a real-world setting in Italy. Clin Ther. 2015;37(3):574-84. doi:10.1016/j. clinthera.2014.11.015.

16. Ostawal A, Mocevic E, Kragh N, Xu W. Clinical effectiveness of liraglutide in type 2 diabetes treatment in the real-world setting: a systematic literature review. Diabetes Ther. 2016;7(3):411-38.

17. Heymann A, Maor Y, Goldstein I, Todorova L, Schertz-Sternberg P, Karasik A. Efficacy of liraglutide in a real-life cohort. Diabetes Ther. 2014;5(1):193-206.

18. Russo GT, Labate AM, Giandalia A, et al. Twelve-month treatment with liraglutide ameliorates visceral adiposity index and common cardiovascular risk factors in type 2 diabetes outpatients. J Endocrinol Investig. 2015;38(1):81-9.

19. National Institute for Health and Clinical Excellence (NICE). Type 2 diabetes in adults: management NICE guidelines [NG28]. http://www.nice. org.uk/guidance/ng28/chapter/1-Recommendatio ns\#hba1c-measurement-and-targets. Accessed Feb 3,2016 .

20. Ponzani P. Long-term effectiveness and safety of liraglutide in clinical practice. Miner Endocrinol. 2013;38(1):103-12.

21. Chitnis AS, Ganz ML, Benjamin N, Langer J, Hammer M. Clinical effectiveness of liraglutide across body mass index in patients with type 2 diabetes in the United States: a retrospective cohort study. Adv Ther. 2014;31(9):986-99.

22. Cigrovski Berković M, Herman Mahečić D, Gradišer M, Bilić-Ćurčić I. Impact of health policy and practice on finding the best fit for patients with type 2 diabetes after metformin failure: Croatian pilot study. Prim Care Diabetes. 2017;11(3):265-72. doi:10.1016/j.pcd.2017.02.004.

23. Rondinelli M, Rossi A, Gandolfi A, et al. Use of liraglutide in the real world and impact at 36 months on metabolic control, weight, lipid profile, blood pressure, heart rate, and renal function. Clin Ther. 2017;39(1):159-69. doi:10.1016/j.clinthera. 2016.11.001.9.

24. Tamura K, Minami K, Kudo M, Iemoto K, Takahashi $\mathrm{H}$, Seino S. Liraglutide improves pancreatic beta cell mass and function in alloxan-induced diabetic mice. PLoS One. 2015;10(5):e0126003. doi:10.1371/ journal.pone.0126003.

25. Moffett RC, Patterson S, Irwin N, Flatt PR. Positive effects of GLP-1 receptor activation with liraglutide on pancreatic islet morphology and metabolic control in C57BL/KsJ db/db mice with degenerative diabetes. Diabetes Metab Res Rev. 2015;31(3):248-55. doi:10.1002/dmrr.2608.

26. Armstrong MJ, Houlihan DD, Rowe IA, et al. Safety and efficacy of liraglutide in patients with type 2 diabetes and elevated liver enzymes: individual patient data meta-analysis of the LEAD program. Aliment Pharmacol Ther. 2013;37(2):234-42. doi:10.1111/apt.12149.

27. Armstrong MJ, Gaunt P, Aithal GP, et al. Liraglutide safety and efficacy in patients with non-alcoholic 
steatohepatitis (LEAN): a multicentre, double-blind, randomised, placebo-controlled phase 2 study. Lancet. 2016;387(10019):679-90. doi:10.1016/ S0140-6736(15)00803-X.

28. Zander M, Madsbad S, Madsen JL, Holst JJ. Effect of 6-week course of glucagon-like peptide 1 on glycaemic control, insulin sensitivity, and beta-cell function in type 2 diabetes: a parallel-group study. Lancet. 2002;359:824-30.

29. Nambu T, Matsuda Y, Matsuo K, et al. Liraglutide administration in type 2 diabetic patients who either received no previous treatment or were treated with an oral hypoglycemic agent showed greater efficacy than that in patients switching from insulin. J Diabetes Investig. 2012;4:69-77.

30. Kozawa J, Inoue $\mathrm{K}$, Iwamoto $\mathrm{R}$, et al. Liraglutide is effective in type 2 diabetic patients with sustained endogenous insulin-secreting capacity. J Diabetes Investig. 2012;3:294-7.

31. Jones AG, McDonald TJ, Shields BM, et al. Markers of $\beta$-cell failure predict poor glycemic response to GLP-1 receptor agonist therapy in type 2 diabetes. Diabetes Care. 2016;39(2):250-7.

32. Khan M, Ouyang J, Perkins K, Nair S, Joseph F. Determining predictors of early response to exenatide in patients with type 2 diabetes mellitus. J Diabetes Res. 2015;2015:162718.

33. Pennartz C, Schenker N, Menge BA, et al. Chronic reduction of fasting glycemia with insulin glargine improves first- and second-phase insulin secretion in patients with type 2 diabetes. Diabetes Care. 2011;34:2048-53.

34. Lecube A, Gonzalez C, Morales C. Liraglutide in clinical practice: glycemic control, and predictors of good response. Med Clin. 2016;146(9):414-7.

35. Thayer S, Wei W, Buysman E, et al. The INITIATOR study: pilot data on real-world clinical and economic outcomes in US patients with type 2 diabetes initiating injectable. Ther Adv Ther. 2013;30:1128-40.

36. Ivić V, Blažetić S, Labak I, et al. High-fat high-sugar diet and liraglutide treatment introduce sex specific changes of adipocytokine receptors in the rat brain while metformin has similar effect on both sexes. The Ukrainian Biochemical Journal-special issue/ Vari, Sandor G. (ed.). Kiev, Ukraine: RECOOP HST Association, 2017. p 28.

37. Saunders WB, Nguyen H, Kalsekar I. Real-world glycemic outcomes in patients with type 2 diabetes initiating exenatide once weekly and liraglutide once daily: a retrospective cohort study. Diabetes Metab Syndr Obes. 2016;9:217-23.

38. Hunt B, Ye Q, Valentine WJ, Ashley D. Evaluating the long-term cost-effectiveness of daily administered GLP-1 receptor agonists for the treatment of type 2 diabetes in the United Kingdom. Diabetes Ther. 2017;8(1):129-47. 